\title{
A battery of self-screening instruments and self-reported body frame could not detect eating disorders among college students
}

\author{
Norika Hayakawa ${ }^{1 \dagger}$, Satoshi Tanaka ${ }^{2 *}+\left(\mathbb{0}\right.$, Naoko Hirata ${ }^{3}$, Sachiko Ogino ${ }^{4}$ and Norio Ozaki ${ }^{2,5}$
}

\begin{abstract}
Objective: Although studies have shown inconsistent results in terms of prevalence of eating disorders, the Eating Attitudes Test (EAT-26) was used to screen students for abnormal eating behaviors. The results of the self-reported EAT-26 and body frame, as well as the efficacy of using self-administered questionnaires (SAQs) were examined to detect eating disorders in new college students.

Results: An anonymous questionnaire (EAT-26) was provided to 7738 new students; 4552 (58.8\%) responders were included in the final analysis. Semi-structured interviews were conducted for 131 (1.7\%) students. Among them, 6 students showed a high EAT-26 score, but were not diagnosed with an eating disorder based on the Structured Clinical Interview for DSM-IV Axis I Disorders (SCID-I). Three students were diagnosed with an eating disorder using SCID-I, but their EAT-26 scores were below the threshold. From these results, in a non-clinical population, findings on EAT-26 do not agree with those on SCID-I in terms of the diagnosis of eating disorders, and this battery is not appropriate for detecting eating disorders.
\end{abstract}

Keywords: Eating disorder, Questionnaire, Prevalence, College students, Eating Attitudes Test

\section{Introduction}

Community-based prevalence studies indicate that the number of people having sub-clinical eating disorders [1] is much larger than those actually diagnosed with it. Prevention, early detection, and early therapeutic intervention [2-5] are important because once an eating disorder develops, patients often lack the motivation to recover or may resist therapy and support.

Among the psychometric tools and batteries developed to detect abnormal eating behaviors [6-9], the Eating Attitudes Test 26 (EAT-26) is a low-cost and precise screening tool used worldwide. It was originally developed by Garner and Garnkel as a 40-item questionnaire for assessing clinical symptoms of eating disorders $[10$,

\footnotetext{
*Correspondence: tanakas@med.nagoya-u.ac.jp

${ }^{\dagger}$ Norika Hayakawa and Satoshi Tanaka contributed equally to this article

2 Department of Psychiatry, Nagoya University Hospital, Nagoya 466-8560, Japan

Full list of author information is available at the end of the article
}

11]. Even its Japanese version [12] is consistent in terms of reliability and external validity.

Although several studies in Japan have used EAT-26 to detect eating disorders and abnormal eating behaviors at the peak age of onset among female students (i.e., high school and college students) [13-16], the results on its prevalence have been inconsistent owing to the small sample sizes and the single use of self-administered questionnaires (SAQs). Several reported findings outside Japan using both the EAT-26 and structured interviews to precisely determine the prevalence of these disorders also yielded uncertain and inconsistent results; for example, Rauof et al. did not test its external validity directly [17]. Rivas et al. reported that the EAT-26 had good specificity but insufficient sensitivity to detect eating disorders [18].

First, can questionnaire-based studies detect eating disorders precisely in the general population? To examine if the EAT-26 along with a semi-structured interview could detect eating disorders at the peak age of onset among 
Japanese college students, we performed a prevalence study with a relatively large sample size.

\section{Main text \\ Methods}

Additional file 1 shows the flow of the study. All new students were recruited to participate in this study from a single college in Japan having two separate campuses. They were recruited in 2012 on one campus, and from 2013 to 2015 on both campuses. The purpose of the study, its methods, and how data from questionnaires would be used were communicated in writing to all the participants. While most participants completed the questionnaires anonymously; those who agreed to undergo a semi-structured interview had to provide their names and contact information. After the questionnaires were retrieved, the staff contacted each participant who had consented to an interview, and explained verbally and in writing, the purpose, methods and how data would be used.

\section{Anonymous questionnaire survey}

EAT-26 is a SAQ that reveals abnormal eating behaviors. It consists of 26 items with six components scored from 0 to 3 (Zero: "Never," "Rarely," and "Sometimes"; 1: "Often"; 2: "Very often"; and 3: "Always"). The total score ranged from 0 to 78 , and a score $\geq 20$ was considered to represent abnormal eating attitudes or behaviors [10,11].

The EAT-26 questionnaire was distributed to 7738 new college students from 2012 to 2015, during their college entrance medical checkup. Students who agreed to participate in the study, had to complete the questionnaire and place it in a collection box in a sealed envelope, while those who did not consent were asked to place blank forms.

Respondents ( $\mathrm{n}=5275,68.2 \%)$ had to provide selfreported body weight and height on the questionnaire. BMI was calculated from these data and classified by the standards of the World Health Organization for people $\geq 20$ years [19].

\section{Semi-structured interview}

We contacted 131 subjects (1.7\%) who agreed to undergo a semi-structured interview. A clinical psychologist or a psychiatrist conducted the interviews that consisted of questions on SCID-I, module $\mathrm{H}$, that covered the diagnosis of eating disorders. All interviews took place in a private room.

\section{Statistical analysis}

Participating students' demographics were compared using their $\mathrm{t}$-test scores. Comparisons were made between males and females, in general as well as those with eating disorders based on EAT-26 and SCID-I findings, respectively. BMIs of participants with high $(\geq 20)$ versus low EAT-26 scores were compared using a MannWhitney U test. All data were analyzed with Excel 2013 (Microsoft Corp., Redmond, WA, USA) and JMP 12.0 for Macintosh (SAS Institute Japan, Tokyo, Japan). In these analyses, $\mathrm{p}<0.05$ was considered statistically significant.

\section{Results}

A total of 5275 (68.2\%) students completed the questionnaire. Forms with missing values on any item of EAT$26(n=241)$, sex $(n=43)$, and body weight or height $(\mathrm{n}=473)$ were excluded from the data analysis. Table 1 shows participants' demographics. The age and BMI of males were significantly higher than females, while EAT26 scores were significantly higher in females than in males. EAT-26 scores of 40 males (2.2\%) and 122 females (4.4\%) were $\geq 20$ (Additional file 2). Among these participants, male students were significantly older and had a significantly higher BMI and significantly lower Eating Disorder Inventory (EDI)-26 score than female students.

The 825 students (18.1\%) classified as underweight $(\mathrm{BMI}<18.5)$, included 246 males $(13.7 \%)$ and 579 females (21.0\%), while the 218 students $(4.8 \%)$ classified as overweight (BMI $\geq 25.0)$, included 139 males $(7.7 \%)$ and 79 females (2.9\%). The majority of the students (3509; 77.1\%) were classified as normal weight $(\mathrm{BMI} \geq 18.5$ to $<25)$.

Among the 162 students with high EAT-26 scores (40 males and 122 females), the break-up was as follows: underweight: 1 male (2.5\%) and 12 females (9.8\%); overweight: 12 males (30.0\%) and 6 females (4.9\%); and normal weight: 27 males (67.5\%) and 104 females (85.2\%).

Additionally, the median BMI $\left(22.4 \mathrm{~kg} / \mathrm{m}^{2}\right)$ of male students with high EAT-26 scores was significantly higher $(\mathrm{p}<0.0001)$ than that of male students with low EAT-26 scores $\left(20.7 \mathrm{~kg} / \mathrm{m}^{2}\right)$. The same trend was seen in female

Table 1 Demographics of the study participants $(n=4552)$ who answered the questionnaire

\begin{tabular}{llll}
\hline & Males $(\mathbf{n = 1 8 0 0})$ & $\begin{array}{l}\text { Females } \\
(\mathbf{n = 2 7 5 2})\end{array}$ & $\begin{array}{l}\text { p value } \\
\text { (Student's t } \\
\text { test) }\end{array}$ \\
\hline $\begin{array}{lll}\text { Age (years) } \\
\text { Mean } \pm \text { SD }\end{array}$ & $18.2 \pm 0.7$ & $18.1 \pm 0.4$ & $<0.0001$ \\
Median (range) & $18.0(17.0-27.0)$ & $18.0(17.0-29.0)$ & - \\
BMI (kg/m $\left.{ }^{2}\right)$ & & & $<0.0001$ \\
Mean \pm SD & $21.1 \pm 2.8$ & $20.1 \pm 2.1$ & - \\
Median (range) & $20.7(13.3-43.1)$ & $19.8(9.3-33.3)$ & $<0.0001$ \\
EAT-26 score & & & - \\
Mean \pm SD & $3.7 \pm 5.4$ & $5.8 \pm 6.8$ & \\
Median (range) & $2.0(0-78.0)$ & $4.0(0-56.0)$ & \\
\hline
\end{tabular}


Table 2 Demographics of participants who underwent a semi-structured interview

\begin{tabular}{lll}
\hline & Males $(\mathbf{n}=\mathbf{4})$ & Females $(\mathbf{n}=\mathbf{1 2 7})$ \\
\hline Age (years) & & \\
Mean \pm SD & $18.0 \pm 0.0$ & $18.2 \pm 0.8$ \\
Median (range) & $18.0(18.0-18.0)$ & $18.0(18.0-26.0)$ \\
BMl $\left(\mathrm{kg} / \mathrm{m}^{2}\right)$ & & \\
Mean \pm SD & $24.0 \pm 2.3$ & $20.4 \pm 2.1$ \\
Median (range) & $23.8(22.0-26.4)$ & $20.0(15.8-28.5)$ \\
EAT-26 score & & $6.3 \pm 6.6$ \\
Mean \pm SD & $4.8 \pm 8.2$ & $5.0(0-32.0)$ \\
Median (range) & $1.0(0-17.0)$ & \\
\hline
\end{tabular}

Table 3 Profiles of students with a high EAT-26 score $(\geq 20)$ and a lack of diagnosis on SCID-I $(n=6)$

\begin{tabular}{lllll}
\hline & EAT-26 & Sex & BMI $\left(\mathbf{k g} / \mathbf{m}^{\mathbf{2}}\right)$ & $\begin{array}{l}\text { SCID-I eating } \\
\text { disorder } \\
\text { diagnosis }\end{array}$ \\
\hline Student 1 & 28 & Female & 19.5 & No \\
Student 2 & 32 & Female & 23.4 & No \\
Student 3 & 22 & Female & 23.9 & No \\
Student 4 & 27 & Female & 18.0 & No \\
Student 5 & 25 & Female & 22.0 & No \\
Student 6 & 30 & Female & 20.3 & No
\end{tabular}

SCID-I Structured Clinical Interview for DSM-IV Axis I

students (median BMI $20.6 \mathrm{~kg} / \mathrm{m}^{2}$ versus $18.6 \mathrm{~kg} / \mathrm{m}^{2}$, respectively; $\mathrm{p}<0.0001$ ).

A total of 131 students underwent a semi-structured interview. Their demographics are shown in Table 2. Six female students had high EAT-26 scores $(\geq 20)$, but did not meet the criteria for eating disorders as described by SCID-I (Table 3).

Only two students diagnosed with an eating disorder by SCID-I showed a low EAT-26 score. Of them, the one was diagnosed with bulimia nervosa (BN), but was suspected of having a history of diagnostic migration from AN. She had a normal BMI and an extremely low EAT-26 score. The other was also diagnosed with $\mathrm{BN}$ with normal BMI and had an EAT-26 score below the cut-off point.

\section{Discussion}

\section{Anonymous EAT-26 survey}

Females had significantly higher EAT-26 scores than males, which is consistent with previous reports [20-23]. This may mean that female students in this generation are keenly interested in dieting and thus tend to experience abnormal eating attitudes and behaviors.
A high EAT-26 score was observed in $2.2 \%$ of the males and $4.4 \%$ of the females (3.6\% of the total). Previous studies in Japan have reported various rates of high $(\geq 20)$ EAT-26 scores. Mase et al. reported high EAT-26 scores in $3.2 \%$ of female college and university students [22], Makino et al. reported high EAT-26 scores in 5.1\% of female college students [23], and Sasai et al. reported high EAT-26 scores in $8.7 \%$ of female college students [14]. Okamoto et al. reported that $0.7-0.9 \%$ of male students and 1.9-2.0\% of female students showed high EAT-26 scores from 2002 to 2010 [24]. These results from Japanese students show a lower prevalence of high EAT-26 scores than results of similar age students outside Japan, in which scores ranged from about 15 to $17 \%$ $[7,9]$. These inconsistencies may be due to differences in ethnicity (our study included mostly Asian islanders), cultural differences, or subtle differences in age or survey methods (e.g., questionnaires sent by post or handdelivered, anonymous or non-anonymous). In addition, results may have differed if other studies included educational documents for eating disorders with the EAT-26. Constarelli and Patsai reported that EAT-26 scores tend to get higher during the examination period in colleges compared to a control period [25]. Results of our study may have been biased because it was done at the time of entrance to college, which can result in low levels of stress after passing the admission exam.

In this study, participants classified as underweight had low EAT-26 scores, potentially suggesting that underweight students may not declare abnormal eating attitudes or behaviors. A similar potential bias based on a different subjective survey was reported by Beglin and Fairburn [26], and a previous study hypothesized that these biases could be related to psychological denial or hesitancy in reporting abnormal eating behaviors in nonanonymous questionnaires [24].

\section{Semi-structured interview}

Only four male participants underwent a semi-structured interview; therefore, the findings from our semistructured interview survey are limited actually to female students. The prevalence of a high EAT-26 score in the semi-structured interview was $4.6 \%(n=6)$, that was close to the results of the anonymous questionnaire. Five out of these six students' BMI was in the normal range. No student having a high EAT-26 score was diagnosed as having an eating disorder based on SCID-I. However, 2 females (1.5\%) whose BMI was in normal range were diagnosed with an eating disorder based on a low EAT26 score. Using SCID-I, EAT-26, and Bulimic Inventory Test, Edinburgh (BITE) for Japanese college students $(n=357)$, Hisamatsu et al. reported that the sensitivity of EAT-26 was low (51.2\%), while the combination of 
EAT-26 and BITE improved the sensitivity to 80.5\% [27]. Jacobi et al. reported that almost all screening tools for abnormal eating behaviors are suitable for clinical cases, but that these tools are not appropriate for the identification of at-risk eating behaviors [28].

Our findings as well as those from previous studies reveal that when a battery of SAQs like EAT-26, selfreported $\mathrm{BMI}$, and semi-structured interviews are used in a non-clinical population, it is not possible to identify subjects with an eating disorder. Better screening tools and objective physical measurements of height and weight are needed to provide a more accurate diagnosis.

\section{Limitations}

- Analysis were limited to only participants who had agreed to participate in the survey; hence, the prevalence of disease is likely to be underestimated.

- SAQs and self-declared body frame are dependent on participants' honesty, hence in principle, their accuracy is limited.

- Only $1.7 \%$ of new students were included in our semi-structured interview, so the results could not be statistically analyzed and hence cannot be generalized to the entire population.

\section{Supplementary information}

Supplementary information accompanies this paper at https://doi. org/10.1186/s13104-019-4672-7.

\section{Additional file 1. Study flow and participants.}

Additional file 2. Numbers of students from questionnaire survey, classified by EAT-26 results, gender and BMI range. Low EAT-26 score: $<20$, high EAT-26: $\geq 20$.

\section{Abbreviations}

EAT-26: Eating Attitudes Test; SAQs: self-administered questionnaires; SCID-I: Structured Clinical Interview for DSM-IV Axis I Disorders; BMI: body mass index; EDI: Eating Disorder Inventory; BITE: Bulimic Inventory Test, Edinburgh; AN: anorexia nervosa; BN: bulimia nervosa.

\section{Acknowledgements}

We are grateful to the students who participated in this study. We would like to thank Editage (http://www.editage.com) for English language editing.

\section{Authors' contributions}

Conceptualization, N. Hayakawa, ST, and NO; methodology, N. Hayakawa, ST, and NO; formal analysis, N. Hayakawa; data curation, N. Hayakawa, ST, N. Hirata, SO; writing —original draft preparation, N. Hayakawa and ST; writingreview and editing, N. Hayakawa and ST; visualization, N. Hayakawa and ST; supervision, NO; project administration, N. Hayakawa; funding acquisition, N. Hayakawa and ST. All authors read and approved the final manuscript.

\section{Funding}

This research was funded by Grants-in Aid from the Japan Society for the Promotion of Science, KAKENHI grant numbers 26461775 in the design of the study and in collection, analysis and interpretation of data, and 17K10344 in writing of the manuscript, the Nanzan University Pache Research Subsidy I-A-2 for the academic year 2017 in collection, analysis and interpretation of data, and Grants-in Aid for Research on Measures for Intractable Diseases from the Ministry of Health, Labour and Welfare of Japan in the design of the study.

\section{Availability of data and materials}

The original dataset of this article cannot be shared based on the decision of the ethics review committee.

\section{Ethics approval and consent to participate}

This study was conducted according to the protocol approved by Nanzan University's committee for research screening, and the ethics review committees at Nagoya University Graduate School of Medicine and Nagoya University Hospital. All the participants provided their written informed consent to participate in one or both stages of the study, as applicable. If a participant was younger than 20 years, written informed consent from his/her parent was also obtained.

\section{Consent for publication}

Not applicable.

\section{Competing interests}

The authors declare that they have no competing interests.

\section{Author details}

${ }^{1}$ Nanzan University, Nagoya 466-0824, Japan. ${ }^{2}$ Department of Psychiatry, Nagoya University Hospital, Nagoya 466-8560, Japan. ${ }^{3}$ Toyoake-shi Government Office, Toyoake 470-1112, Japan. ${ }^{4}$ Aisei Century Hospital, Nagoya 457-8515, Japan. ${ }^{5}$ Nagoya University Graduate School of Medicine, Nagoya 466-8550, Japan.

Received: 7 Auqust 2019 Accepted: 19 September 2019

Published online: 23 September 2019

References

1. Solmi F, Hotopf M, Hatch SL, Treasure J, Micali N. Eating disorders in a multi-ethnic inner-city UK sample: prevalence, comorbidity and service use. Soc Psychiatry Psychiatr Epidemiol. 2016;51:369-81.

2. Nazar BP, Gregor LK, Albano G, Marchica A, Coco GL, Cardi V, Treasure J. Early response to treatment in eating disorders: a systematic review and a diagnostic test accuracy meta-analysis. Eur Eat Disord Rev. 2017;25:67-79.

3. Funari M. Detecting symptoms, early intervention, and preventative education: eating disorders \& the school-age child. NASN Sch Nurse. 2013;28:162-6.

4. Zipfel S, Giel KE, Bulik CM, Hay P, Schmidt U. Anorexia nervosa: aetiology, assessment, and treatment. Lancet Psychiatry. 2015;2:1099-111.

5. Hay PJ, Touyz S, Sud R. Treatment for severe and enduring anorexia nervosa: a review. Aust N Z J Psychiatry. 2012;46:1136-44.

6. Yu J, Lu M, Tian L, Lu W, Meng F, Chen C, Tang T, He L, Yao Y. prevalence of disordered eating attitudes among university students in Wuhu, China. Nutr Hosp. 2015;32:1752-7.

7. Austin SB, Ziyadeh NJ, Forman S, Prokop LA, Keliher A, Jacobs D. Screening high school students for eating disorders: results of a national initiative. Prev Chronic Dis. 2008;5:A114.

8. Reyes-Rodriguez ML, Franko DL, Matos-Lamourt A, Bulik CM, Von Holle A, Camara-Fuentes LR, Rodriguez-Anglero D, Cervantes-Lopez S, Suarez-Torres A. Eating disorder symptomatology: prevalence among Latino college freshmen students. J Clin Psychol. 2010;66:666-79.

9. Prouty AM, Protinsky HO, Canady D. College women: eating behaviors and help-seeking preferences. Adolescence. 2002;37:353-63.

10. Garner DM, Garfinkel PE. The Eating Attitudes Test: an index of the symptoms of anorexia nervosa. Psychol Med. 1979;9:273-9.

11. Garner DM, Olmsted MP, Bohr Y, Garfinkel PE. The eating attitudes test: psychometric features and clinical correlates. Psychol Med. 1982;12:871-8.

12. Nakai Y. Validity of Eating Attitudes Test (EAT). Seishin Igaku. 2003;45:161-5.

13. Mase T, Miyawaki C, Kouda K, Fujita Y, Ohara K, Nakamura H. Relationship of a desire of thinness and eating behavior among Japanese underweight female students. Eat Weight Disord. 2013;18:125-32. 
14. Sasai K, Tanaka K, Hishimoto A. Alexithymia and its relationships with eating behavior, self esteem, and body esteem in college women. Kobe J Med Sci. 2011;56:E231-8.

15. Makino M, Hashizume M, Yasushi M, Tsuboi K, Dennerstein L. Factors associated with abnormal eating attitudes among female college students in Japan. Arch Womens Ment Health. 2006;9:203-8.

16. Nakamura K, Hoshino Y, Watanabe A, Honda K, Niwa S, Tominaga K, Shimai S, Yamamoto M. Eating problems in female Japanese high school students: a prevalence study. Int J Eat Disord. 1999;26:91-5.

17. Rauof M, Ebrahimi H, Asghari Jafarabadi M, Malek A, Babapour Kheiroddin J. Prevalence of eating disorders among adolescents in the Northwest of Iran. Iran Red Crescent Med J. 2015;17:e19331.

18. Rivas T, Bersabe R, Jimenez M, Berrocal C. The Eating Attitudes Test (EAT26): reliability and validity in Spanish female samples. Span J Psychol. 2010;13:1044-56.

19. Body mass index-BMI. http://www.euro.who.int/en/health-topics/ disease-prevention/nutrition/a-healthy-lifestyle/body-mass-index-bmi. Accessed 1 July 2019.

20. Memon AA, Adil SE, Siddiqui EU, Naeem SS, Ali SA, Mehmood K. Eating disorders in medical students of Karachi, Pakistan-a cross-sectional study. BMC Res Notes. 2012;5:84.

21. Hinokuma Y, Kodama K. The relation between eating disorder tendency and ego identity in university students. Bull Train Res Center Clin Psychol. 2010;9:91-106 (in Japanese).
22. Mase T, Miyawaki C, Kouda K, Fujita Y, Okita Y, Ohara K, Mimasa F, Nakamura $\mathrm{H}$. Association between normal weight obesity and diet behaviors in female students. Nihon Koshu Eisei Zasshi. 2012;59:371-80 (in Japanese)

23. Makino M, Tsuboi K, Dennerstein L. Prevalence of eating disorders: a comparison of Western and non-Western countries. MedGenMed. 2004;6:49

24. Okamoto Y, Miyake Y, Yoshihara M. Eating Attitudes of College Students. Jpn J Psychosom Med. 2013;53:157-64 (in Japanese).

25. Costarelli V, Patsai A. Academic examination stress increases disordered eating symptomatology in female university students. Eat Weight Disord. 2012;17:e164-9.

26. Beglin SJ, Fairburn CG. Evaluation of a new instrument for the detection of eating disorders in community samples. Psychiatry Res. 1992:44:191-201.

27. Hisamatsu Y, Tsuboi K, Tsutsui S, Shinoda T. A study on primary screening method for eating disorder in female university students. Jpn J Psychosom Med. 2000;40:325-31 (in Japanese).

28. Jacobi C, Abascal L, Taylor CB. Screening for eating disorders and high-risk behavior: caution. Int J Eat Disord. 2004;36:280-95.

\section{Publisher's Note}

Springer Nature remains neutral with regard to jurisdictional claims in published maps and institutional affiliations.
Ready to submit your research? Choose BMC and benefit from:

- fast, convenient online submission

- thorough peer review by experienced researchers in your field

- rapid publication on acceptance

- support for research data, including large and complex data types

- gold Open Access which fosters wider collaboration and increased citations

- maximum visibility for your research: over $100 \mathrm{M}$ website views per year

At BMC, research is always in progress.

Learn more biomedcentral.com/submissions 